\title{
Textos em Mídia Jmpressa e Digital: confrontando práticas de leitura e objetos de ensino para a formação de leitores proficientes ${ }^{1}$
}

Texts in Printed and Digital Media: facing Reading practices and TEACHING OBJECTS TO THE TRAINING OF PROFICIENT READERS

\section{Williany Miranda da Silva*}

Resumo: O presente artigo reivindica o lugar pedagógico do texto para o ensino de práticas de leitura utilizados em duas mídias: impressa e digital. Assim, parto da problematização: será que as práticas de leitura reveladas a partir de textos (de mídias impressa e digital) sinalizam a necessidade de novas configurações para a formação de leitores competentes comunicativamente? Para respondê-la, observamos o tratamento dado ao tema "racismo" em atividades de livros didáticos e em comentários em rede social. O confronto dos objetos com base em Coracini (2005), Kleiman (2009), Abreu (2014), Leurquin e Carneiro (2014), dentre outros, possibilitou a identificação de práticas diferenciadas para cada suporte. No livro didático, elas apontam para uma estabilização de sentidos centrado no texto e no autor, típicas na situação de escolarização. Diferentemente, nos comentários, as práticas evidenciam uma estabilização de sentidos focado no leitor, típicas em situação fora do ambiente escolar. O comportamento divergente para a

\footnotetext{
* Mestrado (1997) e Doutorado (2004) em Letras - Linguística pela Universidade Federal de Pernambuco. Professora da Unidade Acadêmica de Letras e membro do Programa de Pós-Graduação em Linguagem e Ensino da Universidade Federal de Campina Grande. Contato: williany.miranda@gmail.com.

${ }^{1}$ Este texto resulta de discussões no Grupo de pesquisa, Teorias da linguagem e ensino, em torno do projeto Novas Configuracões de Ensino de Leitura e Escrita em Atividades de Linguagem (NS) (2014-2017).
} 
produção de sentido sinaliza uma contínua tensão no tratamento dado aos textos e à leitura, destacando a necessidade de ações de planejamento de ensino, considerando a relação entre a diversidade textual e os múltiplos suportes midiáticos para a formação de leitores em sintonia com novas práticas.

Palavras-chave: Leitura. Ensino de textos. Mídia digital.

Abstract: This present work claims the pedagogical place of the text to the teaching of reading practices used in two medias: printed and digital. Therefore, I start from the questioning: do the reading practices revealed from texts (of printed and digital media) indicate the necessity of new configuration to the training of competent readers communicatively? To answer this question, we observed the handling given on the topic "racism", in activities of manuals and in comments on digital media. The comparison of the objects based on the authors such as Coracini (2005), Kleiman (2009), Abreu (2014), Leurquin e Carneiro (2014), among others, enabled the identification of differentiated practices for each support. In the manual, they point to a stabilization of meaning centred in the text and the author, very common in the school situation. However, in the comments, the practices show a stabilization of meaning focused on the reader, typical in situations outside the school. The deviant characteristic to the production of meaning indicates a continuous tension in the handling given to the texts and the reading, highlighting the necessity of a teaching planning, considering the relation between the text diversion and the multiple media support to readers training following the new practices.

Keywords: Reading. Texts teaching. Digital media.

\section{Considerações Iniciais}

O ponto de partida para o presente artigo é a reflexão sobre a diversidade de textos e de práticas de leitura que se realiza em suportes variados - do tradicional livro didático (LD) às postagens que circulam em redes sociais, e rapidamente são visualizadas, curtidas e compartilhadas por milhares de internautas. Nesse sentido, meu interesse volta-se, em 
conformidade com Silva (2008), para o funcionamento do texto em situações concretas de uso cognitivo e social, individual e coletivo, influenciado pelas regras que permeiam as interações sociais e, de acordo com Leurquin e Carneiro (2014), para a apropriação desses usos situados como objeto de ensino de leitura, a depender das escolhas que o professor cria em torno dos saberes que considera relevantes no contexto escolar.

Reivindica-se, nas tarefas relativas à sobrevivência diária de um cidadão comum, leitores habilidosos e com múltiplas competências. De forma veloz, constata-se um fenômeno muito comum aos jovens, que é o acesso à informação para resolver dificuldades escolares ou profissionais, via tecnologia móvel e seus inúmeros aplicativos. Sem muitas dificuldades, organiza-se uma lista de músicas, assiste-se a filmes ou participa-se de redes sociais, interagindo com postagens de vídeos, imagens e/ou comentários sobre assuntos que estão na ordem do dia. Diferentemente, no contexto escolar, jovens brasileiros oferecem resistência ao cumprimento de atividades presentes nos materiais de ensino utilizados ao longo dos anos de escolarização, por exemplo, na discussão de textos, através de atividades que exploram o texto em seus variados aspectos: composição do gênero, contexto de produção, objetivos de leitura, percepção crítica, intertextualidade, dentre outros.

Atitudes tão diferentes num cenário de práticas letradas semelhantes motivou a produção desse artigo. Digo semelhantes porque a presença da multimodalidade e seus diversos modos de representação em textos é fundamental e recorrente, não só para a compreensão de textos da mídia digital, como também em textos da mídia impressa: imagens, formato de letras, cores diferenciadas etc. Assim, definitivamente, esse não é o ponto de discordância para comportamentos tão díspares em relação ao funcionamento sociocomunicativo dos textos e ao consumo de leitura dos dois universos.

A necessidade não só de formar leitores como de abordar as tecnologias digitais em sala de aula tem sido imposta pela burocracia estatal, via documentos oficiais, que, sem negociação com os professores, implementam ações que interferem na sua atuação. Para minimizar tais efeitos, oportunizam-se cursos envolvendo as tecnologias de informação e incentivam-se projetos que considerem a mídia digital. Assim, os docentes, a 
despeito de toda e qualquer resistência, começam a ver suas rotinas comprometidas em direção a uma suposta renovação do ensino muito mais pela pressão social do que pelas necessidades dos discentes ou por motivos pedagógicos (BUIN, 2007).

Assim, em face desse contexto, parto da seguinte problematização: será que as práticas de leitura reveladas em textos (de mídias impressa e digital) sinalizam a necessidade de novas configurações para a formação de leitores competentes comunicativamente? Por "práticas de leitura" estou considerando a interrelação, realizada pelo leitor, de um conjunto de atividades, envolvendo o código, as imagens e o contexto sociocomunicativo para dar conta da complexa tarefa de acessar as informações, vislumbrar intenções e motivações para a compreensão e circulação de um texto em suportes variados (KLEIMAN, 2009). Para o artigo em questão, tais práticas foram evidenciadas ante a expectativa de resposta do aluno ou manifestação escrita do usuário de redes sociais sobre um mesmo tema "racismo". Este se fazia presente tanto na seleção de textos (crônica e cartuns) e respostas às atividades de interpretação em meio impresso (livro didático ${ }^{2}$ ) quanto em postagens sobre uma reportagem ${ }^{3}$ em meio digital.

Posta a questão-problema, procurei um diálogo entre teorias e objetos, a fim de, no entrecruzamento de mídias, contribuir para dimensionar o ensino de leitura e sua relação com a diversidade de textos na mídia impressa e na mídia digital. Além disso, refletir sobre o papel do professor como mediador na formação de leitores proficientes em ambientes (não) escolares. Apesar de tratar-se de um tema de ampla produção de conhecimento, bastante difundido e estabilizado na academia, é urgente que seja revisitado e analisado à luz de outros espaços de linguagem, a exemplo do espaço promovido pela mídia digital, por exemplo.

Meus objetivos específicos são confrontar as práticas de leitura requeridas nos textos veiculados na mídia impressa com as evidenciadas nos textos que circulam na mídia digital; além de relacioná-las às estratégias de ensino mobilizadas pelos professores para promover leitores crítico-reflexivos. Essa preocupação justifica-se por considerarmos que a formação de leitores, enquanto sujeitos sociais, vincula-se ao que se faz, não apenas na, mas fora da

${ }^{2}$ Livro do $8^{\circ}$ ano da Coleção Português: linguagens, de Cereja e Magalhães (2014).

${ }^{3}$ Disponível em: $<$ https://www.youtube.com/watch?v=PH8vkEybJbA $>$. 
escola, em outras instâncias de letramento, genericamente denominada sociedade. Assim, escola e sociedade se configuram como fundamentais para a formação da cidadania de um povo dito civilizado. Por essa razão, é oportuna a compreensão das necessidades informacionais veiculadas e projetadas ante a diversidade textual que é produzida e que circula nos diferentes suportes em meios impressos e digitais (FREIRE, 2008).

A investigação segue por dois encaminhamentos teórico-analíticos: o primeiro deles reflete sobre a noção de texto e as práticas de leitura subjacentes aos dois conjuntos de dados, subsidiados por Coracini (2005), Kleiman (2009) e outros. O segundo encaminhamento, por sua vez, relaciona as práticas supracitadas ao processo de didatização da leitura em diferentes suportes e suas implicações para o ensino. Para tanto, serão tomados como referência autores como Leurquin e Carneiro (2014) e Abreu (2014), entre outros.

Os dados coletados para o desenvolvimento da presente pesquisa são de caráter documental e reconhecidos pelos linguistas aplicados como pertinentes, dentro de uma nova configuração, em que se assume a Linguística Aplicada (LA). Esta abordagem está para além do foco de onde partiram os primeiros estudos dessa área interdisciplinar, percebida como mediadora entre as investigações sobre o ensino de línguas estrangeiras e língua materna (ARAÚJO, 2014, p. 222). É na fronteira entre concepções de texto, ensino de leitura e diversidade de materiais disponíveis nos suportes tecnológicos que consiste em outro viés possível para a LA.

\section{Compreendendo os Textos e as Perspectivas de Leitura Subjacentes}

\subsection{Práticas de leitura na mídia impressa}

O primeiro conjunto de dados é pertencente à mídia impressa, do livro didático Português: linguagens, do $8^{\circ}$ ano ${ }^{4}$. Trata-se de três textos (Figuras 1, 2, 3 e 4) de uma unidade de leitura do Capítulo 3 com suas respectivas atividades de interpretação e abordagem da temática desigualdade social e preconceito racial, denominada "O povo: suas cores, suas dores".

${ }^{4}$ De autoria de Cereja e Magalhães, esse livro é parte de uma coleção com quatro volumes, do $6^{\circ}$ ao $9^{\circ}$ ano, adotado e distribuído em várias escolas públicas da cidade de Campina Grande, PB. 
O texto principal é uma crônica de Luís Fernando Veríssimo, intitulada "Povo", cuja temática gira em torno do interesse da patroa (branca) em sair na escola de samba da empregada doméstica (preta). Para complementar as informações do texto, aparecem duas ilustrações, visíveis nas Figuras 1 e 2. Vejamos a Figura 1:

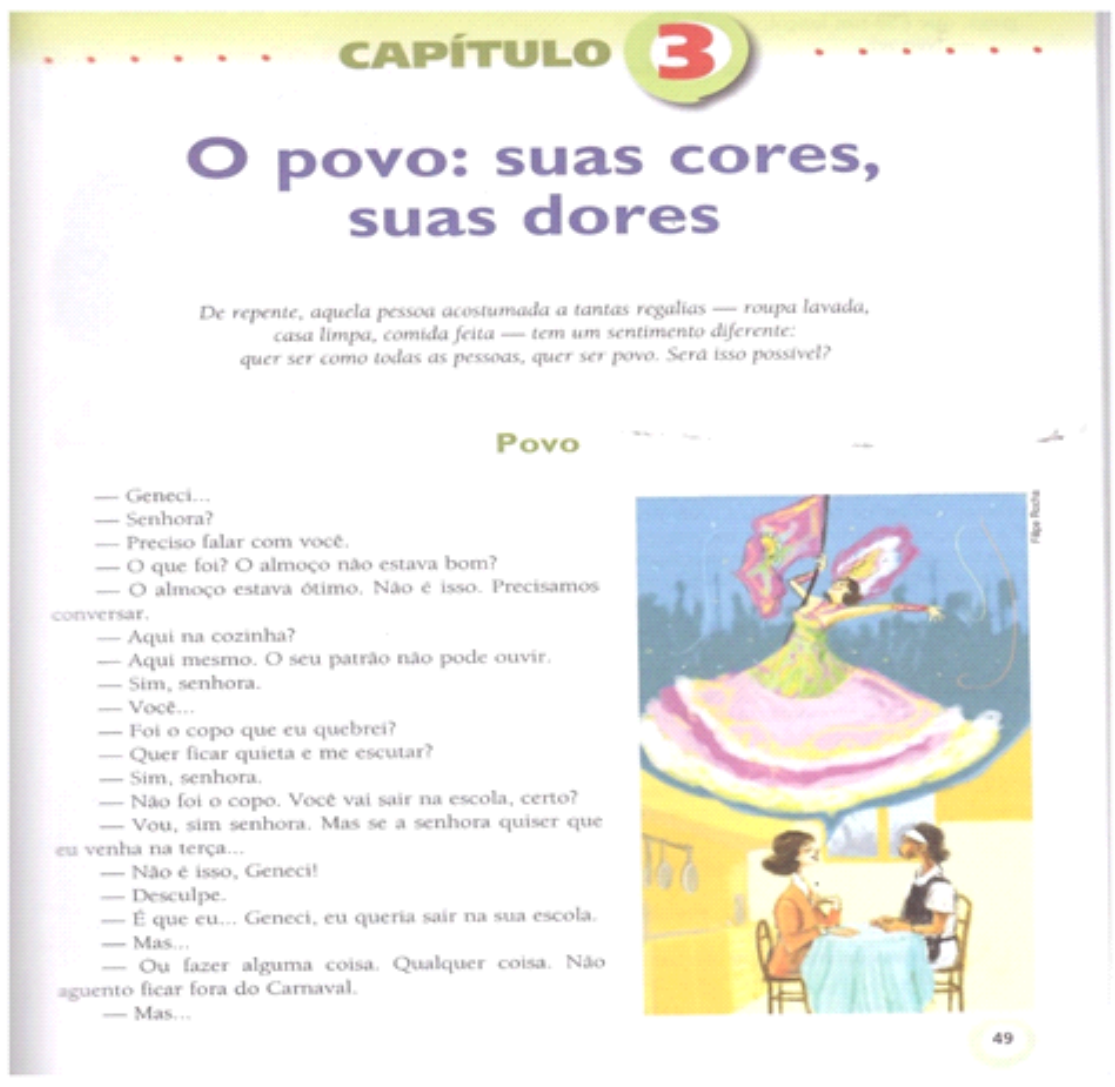

Fonte: Cereja e Magalhães (2014, p. 49).

Figura 1: Crônica "Povo"

Na Figura 1, tem-se uma primeira ilustração: a imagem de uma porta-bandeira e de duas mulheres conversando. Estas mulheres representam, 
respectivamente, a empregada e a patroa, caracterizadas pelas vestimentas. É a versão ilustrada do diálogo da crônica. A Figura 2, ilustrada na sequência, é a continuidade da crônica. Nela, aparecem outra ilustração e um box, com três verbetes para auxiliar na compreensão do código linguístico:

- Vocếs não têm, sei lá, uma ala das patroas? Qualquer coisa.

- Se a senhora tivesse me falado antes.

- Eu sei. Agora é tarde. Para a fantasia e tudo o mais. Mas eu improviso uma baiana. Deusa grega, que é só um lençol.

- Nào sei..

- Saio na bateria. Empurrando alegoria.

- Olhe que nào é fácil.

- Eu sei. Mas eu quero participar. Eu até sambo direitinho. Voce nunca me viu sambar? Nos bailes do clube, por exemplo. Toca um samba e lá vou eu. Até acho que tenho um pe na cozinha. Quer dizer. Desculpe.

- Tudo bem.

- Eu também sou povo, Geneci! Quando vejo uma escola passar, fico toda arrepiada.

- Mas a senhora pode assistir.

- Mas eu quero participar, você nào entende? No meio da massa. Sentir o que o povo sente. Vibrar, cantar, pular, suar.

- Olhe...

- Por que só vocés podem ser povo? Eu também tenho direito.

- Nào sei.

- Se precisar pagar, eu pago

- Não é isso. E que..

- Esta bem. Olhe aqui. Nato preciso nem sair na avenida. Posso costurar. Ajudar a organizar o pessoal. Ajudar no transporte. O Alfa Romeo está af mesmo. Tem a Caravan, se o patrăo nåo der falta. E a emocáo de participar que me interessa, entende? Poder dizer "a minha escola...". Eu teria assunto para o resto do ano. Minhas amigas ficariam loucas de inveja. Alguns iam torcer o nariz, claro. Mas eu nåo sou assim. Eu sou legal. Eu näo sou legal com você, Geneci? Sempre tratei você de igual para igual.

- Tratou, sim senhora.

- Meu Deus, a ama de leite da minha mãe era preta!

- Sim, senhora.

- Geneci, é um favor que vocé me faz. Em nome da nossa velha amizade. Faço qualquer coisa pela nossa escola, Geneci.

- Bom, se a senhora esta mesmo disposta..

- Qualquer coisa, Geneci

- Ê que o Rudinei e Fátima Araci não têm com quem ficar.

- Quem?

- Minhas crianças.

- Ah. eu desfilo.

- Se a senhora pudesse ficar com eles enquanto

- Certo. Bom. Vou pensar. Depois a gente ve.

- Eu posso trazer elas e...

- Já disse que vou pensar, Geneci. Sirva o cafe-

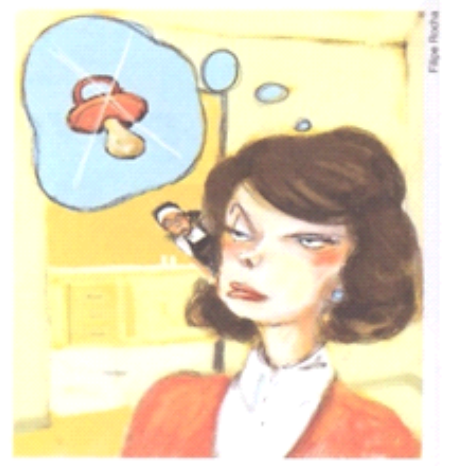
zinho na sala.

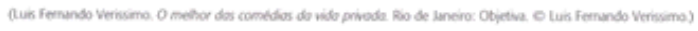

50

Fonte: Cereja e Magalhães (2014, p. 50).

Figura 2: Continuação crônica "Povo"

Signum: Estud. Ling., Londrina, n. 20/1, p. 81-109, abr. 2017 
Isoladamente, as duas ilustrações gerenciam a expectativa do leitor em relação à compreensão e desfecho da crônica, resumido em dois momentos: amigável, encontro cordial entre patroa e empregada, e não amigável, pensamento desagradável da patroa em relação à presença de um bebê, através da chupeta. A leitura do texto confirma essa expectativa e é resgatada através de atividades de leitura que direcionam a interpretação.

As Figuras 3 e 4 reproduzem as atividades referentes à crônica. Elas ilustram 11 questões de compreensão e interpretação referentes à crônica. Para respondê-las, a identificação das informações serve como ponto de partida, embora outras operações sejam solicitadas. Vejamos o exemplo que segue: 


\section{Estudo do texto}

\section{COMPREENSÃO E INTERPRETAÇÃO}

1. Observe que todo o texto é construido em forma de diálogo, isto é, ele reproduz diretamente as falas das personagens, sem intromissão do narrador. Que efeito esse recurso provoca no texto?

2. A patroa conversa com a empregada.

a) Em que lugar ocorre a conversa?

b) $\mathrm{O}$ que Geneci imaginava que a patroa fosse dizer?

c) Pelo início da conversa, como você acha que tem sido a relaçăo entre a patroa e a empregada até o momento? Por quê?

3. A patroa deseja participar do desfile da escola de samba de Geneci. Até então, a patroa tinha mostrado interesse pela escola de samba ou

\section{A crônica e o retrato do cotidiano}

Luis Femàndo Verissimo talvez seja o principal cronista brasileiro da atualidade.

A crónica é um gênero que nasceu no jornal $\mathrm{e}$ está diretamente relacionado com os fatos cotidianos. Com seu olhar sensivel e muitas vezes critico e humoristico, o cronista flagra momentos do cotidiano e dá a eles uma nova significaçào. Ê impossivel ver o mundo da mesma forma dépois da leitura de uma boa cronica.

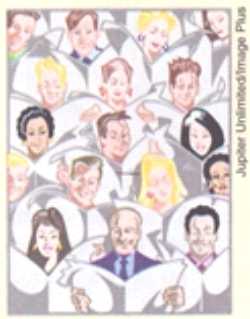
pelo carnaval? Justifique sua resposta.

4. Para convencer Geneci, a patroa utiliza vários argumentos. Veja:

- não quer ficar fora do carnaval

- samba bem

- ela também é povo

- arrepia-se quando a escola de samba passa

- quer sentir o que o povo sente
- pode pagar

- pode ajudar no transporte, nas costuras

- vai ter assunto o resto do ano

- vai causar inveja nas amigas

a) Quais desses itens são argumentos que visavam convencer Geneci?

b) Quais deles revelam os motivos reais de a patroa querer participar do carnaval?

5. Para aproximar-se de Geneci e conseguir seu apoio, a patroa se diz parte do povo e afirma que sempre tratou a empregada de "igual para igual". Observe os pronomes de tratamento utilizados pelas duas.

a) Com que pronome a patroa trata a empregada? E que pronome Geneci utiliza para dirigir-se à patroa?

b) Essas formas de tratamento confirmam a suposta igualdade entre elas?

6. Além de abordar a questão da diferença social, o texto também faz referência à diferença étnica entre as personagens.

a) Qual é a cor da patroa e da empregada?

Fonte: Cereja e Magalhães (2014, p. 51).

Figura 3: Atividades referentes à crônica "Povo"

Signum: Estud. Ling., Londrina, n. 20/1, p. 81-109, abr. 2017 
b) Para justificar que samba bem, a patroa diz "Até acho que tenho um pé na cozinha". O que ela quis dizer com isso?

c) Levante hipóteses: Por que a patroa se desculpa por ter dito que tem "um pé na cozinha"?

7. Segundo o texto, a ama de leite da mãe da patroa era preta. Conclua:

a) Que semelhança há entre Geneci e a ama de leite da mãe da patroa quanto a características profissionais, sociais e étnicas?

b) Que semelhança há entre a patroa e a mãe dela, do ponto de vista social e étnico?

c) Com que finalidade a patroa menciona a ama de leite de sua mãe? Justifique sua resposta.

8. Deixando de lado a relação de patroa e empregada que tinham, a patroa diz: "Em nome da nossa velha amizade. Faço qualquer coisa pela nossa escola, Geneci". Que sentido tem no contexto a palavra nossa, da expressão "nossa escola"?

9. Como a patroa insistisse em colaborar com a escola de samba, Geneci encontra um meio de ela participar: cuidando de seus filhos.

a) Entre amigas, é normal uma cuidar dos filhos da outra?

b) $O$ fato de a patroa não saber quem são Rudinei e Fátima Araci confirma ou nega a amizade entre as duas? Por quê?

c) E a reação da patroa: confirma ou nega a amizade?

10. Observe as duas frases do final do texto.

a) Como você acha que a patroa está se sentindo quando diz "Já disse que vou pensar, Geneci"? Por que ela se sente assim?

b) Qual é o modo verbal utilizado na frase "Sirva o cafezinho na sala"? O emprego desse modo verbal revela o lado patroa ou o lado "amiga" da personagem?

c) A patroa quer ser servida na sala. $O$ emprego da locução adverbial na sala é fundamental para a interpretação geral do texto. Explique por quê.

d) Dê sua opiniāo: A "velha amizade" entre Geneci e a patroa deverá continuar? Por quê?

11. O texto "Povo" é humorístico. Contudo, além de promover o riso, ele tem outra finalidade. Qual é ela?

52

Fonte: Cereja e Magalhães (2014, p. 52).

Figura 4: Continuação das atividades referentes à crônica "Povo" 


\section{Exemplo 1}

\section{A patroa deseja participar do desfile da escola de samba de Geneci. Até então, a patroa tinha mostrado interesse pela escola de samba ou pelo carnaval? Justifique sua resposta.}

O Exemplo 1 destaca uma operação que conduz o leitor para uma resposta, partindo de uma afirmação tida como verdadeira, em "A patroa deseja participar do desfile da escola de samba de Geneci”. A essa informação dada, o leitor é levado a buscar novidades no texto, comparando-as à medida que elas vão aparecendo para construir sua resposta. Outras questões, por sua vez, solicitam uma orientação para além do código, e conduzem o leitor a uma reflexão sobre os objetivos e as intenções da personagem central, enfatizando a compreensão de recursos imagéticos, estilísticos e efeitos de sentido, sem, no entanto, explicitá-los. Vejamos o Exemplo 2, que segue:

\section{Exemplo 2}

\section{Além de abordar a questão da diferença social, o texto também faz referência à diferença étnica entre as personagens.}

a) Qual é a cor da patroa e da empregada?
b) Para justificar que samba bem, a patroa diz "Até acho que tenho um pé na cozinha". 0 que ela quis dizer com isso?

c) Levante hipóteses: Por que a patroa se desculpa por ter dito que tem "um pé na cozinha"?

No Exemplo 2, em dois subtópicos - “a) Qual é a cor da patroa e da empregada?” e “c) Levante hipóteses: Por que a patroa menciona a ama de leite de sua mãe? Justifique sua resposta." - o leitor agrupa as unidades de sentido através do reconhecimento das unidades frasais considerando também outros conhecimentos: o prévio e o textual. Para este último, observa-se a ideia da relação lógico-temporal, enfatizando cenário, personagens e gradação de 
temáticas, a exemplo da afirmação no item 6 , "Além de abordar a questão da diferença social, o texto também faz referência à diferença étnica entre as personagens"; já para aquele, observa- se a ativação de inferências, ao sugerir reflexões sobre a expressão "um pé na cozinha" e levantamento de hipóteses acerca do "pedido de desculpas da patroa".

Ao constatar a diversidade de estratégias empreendidas para a compreensão da crônica, observam-se atividades elaboradas para promover no leitor a ativação de conhecimentos que tornam significativos o processamento no ato de ler (KLEIMAN, 2009). O exemplo a seguir vai na mesma direção:

\section{Exemplo 3}

\section{Segundo o texto, a ama de leite da mãe da patroa era preta. Conclua:}

\section{a) Que semelhança há entre Geneci e a ama de leite da mãe da patroa quanto a caracteristicas profissionais, sociais e étnicas? \\ b) Que semelhança há entre a patroa e a mảe dela, do ponto de vista social e étnico? \\ c) Com que finalidade a patroa menciona a ama de leite de sua mãe? Justifique sua resposta.}

O Exemplo 3, semelhantemente ao Exemplo 2, parte de uma afirmação tomada como verdadeira para que o leitor se situe com relação à solicitação posterior, em "a ama de leite da mãe da patroa era preta". Em ambos, constatam-se propostas de atividades em que se consolidam as formas de processamento do conhecimento linguístico inter-relacionados a outros aspectos, abordando especificamente aspectos discursivos em relação à temática do preconceito racial. Elas são minoria em relação ao total de atividades, o que sinaliza para uma tentativa de homogeneização de sentidos. Esta tentativa não problematiza a relação entre a desigualdade social e a questão racial abordadas. A construção de respostas, para além de um juízo de valor, necessita que sejam considerados aspectos históricos, sociais, culturais e ideológicos, por vezes silenciados na condução do professor. Este acaba por determinar, numa relação de poder, o que pode e deve discutir para sustentar o lugar dos sujeitos (CORACINI, 2005). 
Dando continuidade à unidade do livro, temos a presença de outros dois textos que se organizam de forma diferente do anterior, embora manifestem semelhante necessidade evidenciada nos exemplos analisados. São cartuns e têm o propósito, na unidade, de reforçar a temática ou o conflito anunciado na crônica. Vejamos o cartum reproduzido pela Figura 5:

\section{Leia o cartum abaixo, de Quino.}

Esta criaturinha é filha de gente humilde da regilaso. E nós compramos para ela a roupinha, os brinquedos, tudo. porque, na verdade. nós gostamos dela como se fosse da familia.

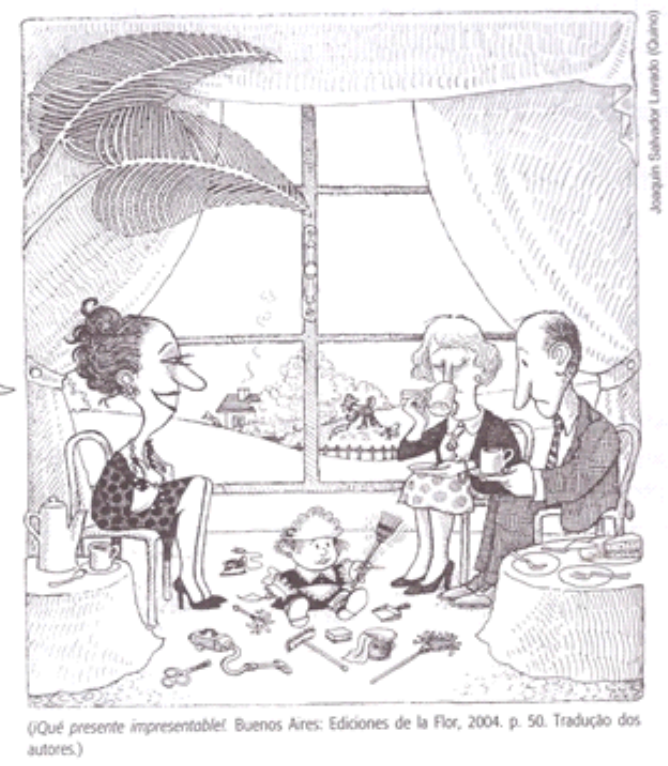

Fonte: Cereja e Magalhães (2014, p. 54).

Figura 5: Cartum de Quino

O cartum é de autoria de Quino e sua presença está inter-relacionada à Questão 3, cuja instrução pode ser constatada no exemplo, a seguir: 


\section{Exemplo 4}

3. Compare o que diz a dona da casa no cartum de Quino e o que diz a patroa da personagem
Geneci no texto "Povo".

"Eu sou legal. Eu nåo sou legal com você,, Geneci? Sempre tratei você de igual para igual."
a) Em que se assemelham?
b) O humor é feito para divertir. Contudo, às vezes, ele pode cumprir outros papéis. Com base nos dois textos, responda: Que outro papel o humor pode ter?

O Exemplo 4 solicita a comparação entre o referido cartum e um fragmento retirado da crônica. Trata-se de um movimento mental de comparação entre uma nova situação posta e uma informação dada. A imagem se integra de forma pertinente a uma situação, aparentemente hipotética, reproduzida no texto literário, conferindo a atualidade da reflexão promovida por ambos os textos, para além da temática da desigualdade social ou preconceito racial, tangenciando o tema para o humor, através da comparação do comportamento das personagens, no fragmento, "Em que se assemelham?", ao questionar "Que outro papel o humor pode ter?", em decorrência da ausência de senso do ridículo presente em ambos os textos.

Vejamos mais um cartum, reproduzido na mesma unidade, na seção "Trocando ideias" (p. 55): 
5. Leia este cartum, de Hubert:

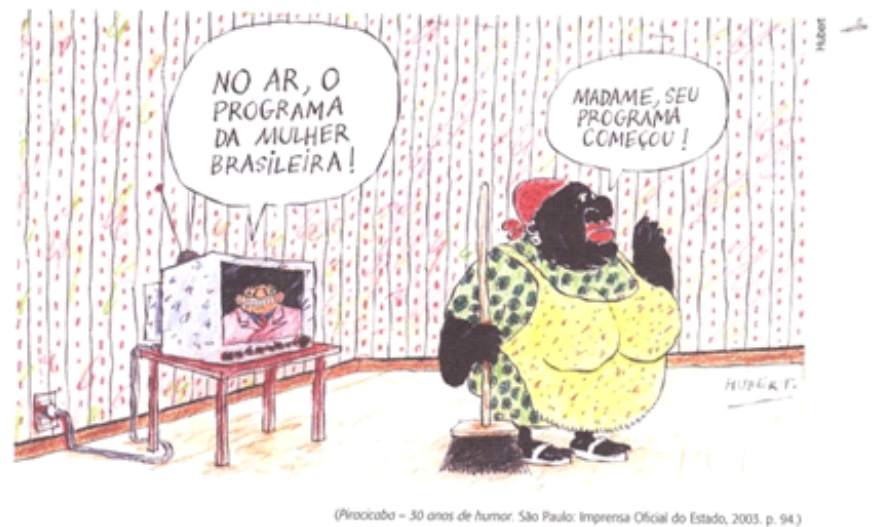

Dê sua opiniâo: Por que a mulher desse cartum nåo se inclui entre as mulheres brasileiras?

Fonte: Cereja e Magalhães (2014, p. 55).

Figura 6: Cartum de Hubert

A Figura 6 reproduz um cartum de Hubert e aparece como parte de uma questão, semelhantemente ao cartum anterior. Entretanto, o seu funcionamento aponta para o fechamento da unidade de leitura, com uma questão mais geral, reproduzida no Exemplo 5, a seguir:

\section{Exemplo 5}

De sua opiniâo: Por que a mulher desse cartum nåo se inclui entre as mulheres brasileiras?

O Exemplo 5 reporta a uma reflexão que extrapola a discussão promovida pela crônica e pelo cartum anterior (Figura 5). Contudo, a possibilidade em opinar, oportuniza a mobilização, por parte do leitor, de diversos conhecimentos, empreendendo um exercício de cidadania cuja noção de leitura vai além da perspectiva cognitiva e metacognitiva reportadas. 
Não se trata apenas (e não é pouco!) de estabelecer uma relação em que se conhece a língua, o gênero, conhecimento de mundo ou prévio para se estabelecer analogias ou comparações entre os temas veiculados nos textos. Há que se ter mais propriedade sobre o aspecto histórico e social nas produções linguageiras, na integração entre o linguístico e a imagem do cartum em foco. Estas produções "geralmente se articulam a ações coletivas complexas e se encontram estreitamente relacionadas à realização de ações não verbais, a intervenções sobre o ambiente ou a manipulações de objetos, o que requer uma abordagem multimodal (BRONCKART, 2008, p. 106).

Ao solicitar do aluno "Dê sua opinião", corre-se o risco de se aceitar uma livre resposta que aponte para qualquer direção. A ausência de uma reflexão sobre a implicação de gêneros, na compreensão textual, dificulta a percepção da linguagem como ação e a necessidade de relacioná-la às práticas sociais reais, promovendo um distanciamento entre o que se pratica na e fora da escola.

Como aspecto positivo, destacamos a adequação entre a escolha de textos variados (Figuras 1, 2, 5, 6) e sua interrelação com as estratégias de compreensão mobilizadas nas atividades (Figuras 3, 4, 6). Tal adequação advém de um consenso teórico, mobilizado pelos autores do LD, corroborando a ideia de que "o texto é um objeto que, apesar de regular, se manifesta como heterogêneo, flexível e multifuncional”" (ANTUNES, 2009, p. 51).

Em se tratando de atividades, por outro lado, evidenciam-se práticas tipicamente escolares, que, embora abordem a leitura para além do tema gerador, no uso de estratégias que exploram graus de compreensão variados e temas derivados, deixam de lado as relações de poder inerentes aos discursos que as respostas promovem.

Em específico, a exploração do tema "racismo" limita-se a um número reduzido de atividades, restritas ao tempo e espaço de sala de aula. Evidente que essa limitação poderia ser ressignificada se houvesse uma reflexão para além da restrição dos papéis sociais, ocupados pelos sujeitos, na condição de alunos e professor, e para além da incompletude do meio (mídia impressa) em que os textos circulam.

Outro aspecto que se constata nesta prática tipicamente escolarizada diz respeito à ausência de uma reflexão sobre a diversidade dos gêneros 
inerente aos textos que compõem a unidade temática. Os aspectos multimodais como o traço e a cor das ilustrações são negligenciados não apenas na crônica; pois os cartuns também não são tomados como objetos de ensino e de aprendizagem em si. Essa negligência contribui para a percepção de uma prática de leitura que toma o texto e o autor, ainda, como determinantes para a produção do sentido (CORACINI, 2005). Mesmo considerando-se os conhecimentos trazidos pelo leitor para a compreensão, esses conhecimentos dependem de uma "autorização" dada pelo texto. Outras possibilidades de construções de sentido não são estimuladas e outras formas de se perceber o dito estão em contínua modificação, dada a multiplicidade de outras demandas de leitura, como as que a mídia digital oportuniza.

\subsection{Práticas de leitura em mídia digital}

O segundo conjunto de dados é proveniente da mídia digital e é composto pela imagem da jornalista Maria Júlia Coutinho (Figura 7), vítima de racismo, da transcrição de uma reportagem publicada pelo apresentador William Bonner, do Jornal Nacional (Figura 8) e de comentários (Figuras 9 e 10) postados em redes sociais sobre a apresentadora. Vejamos a Figura 5, que segue: 


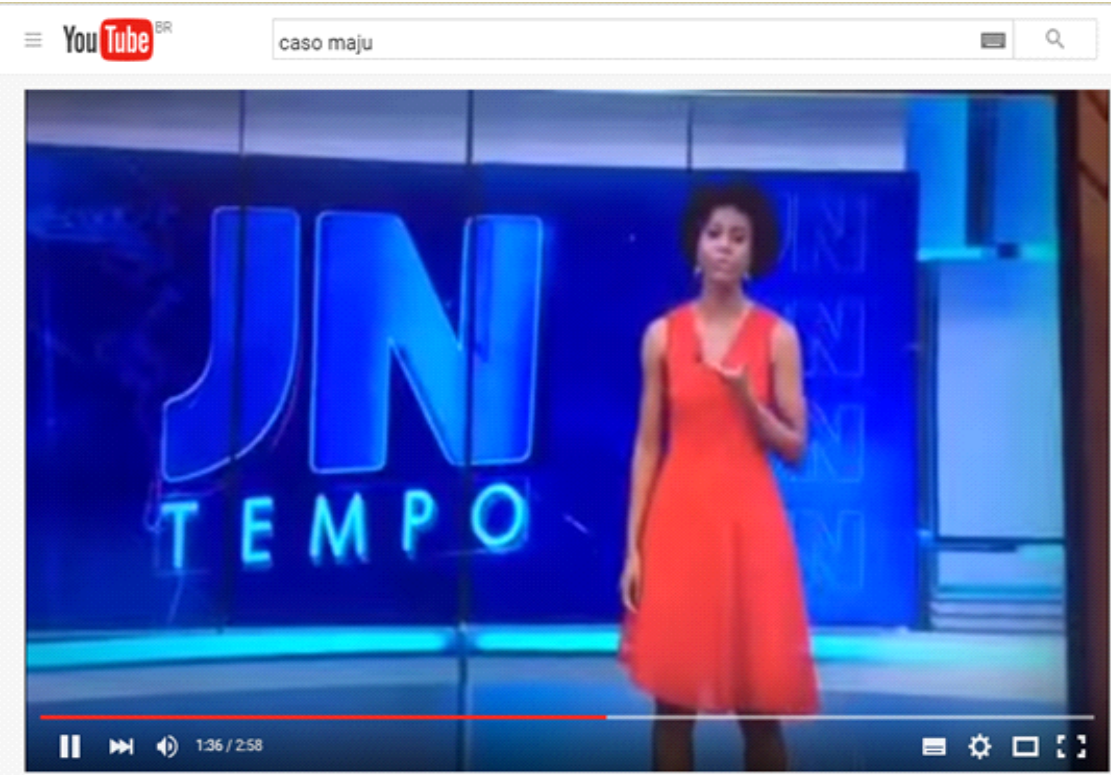

William Bonner interrompe Jornal Nacional para Maju comentar caso racismo enfrentado na net

Fonte: <https://www.youtube.com/watch?v=PH8vkEybJbA>?

Figura 7: Maria Júlia Coutinho, a Maju

A Figura 7 reproduz uma imagem capturada do YouTube, no momento em que o apresentador delibera a palavra à jornalista para falar sobre o ocorrido. Sua repercussão ganhou espaço não só na mídia televisiva, mas em várias redes sociais (Twitter, Instagran, YouTube e Facebook) e, posteriormente, em jornais impressos. Em síntese, o trecho transcrito relata: a) o crime realizado pela internet, com a expressão " 50 criminosos publicaram comentários racistas"; b) a manifestação de solidariedade de internautas, através dos trechos, "milhares e milhares de pessoas manifestaram a indignação e o repúdio aos criminosos" e "Somos todos Maju", c) a reação de autoridades, no trecho, "E isso também

${ }^{5}$ Reportagem exibida em 03 de julho de 2015. Esta reportagem também pode ser encontrada transcrita em: $<$ https: / / www.youtube.com/watch?v $={ }_{\mathrm{o}}$ TEi30gc8Uw $>$. 
acabou provocando a reação das autoridades..." e, por fim, d) o posicionamento da vítima, "eu já lido com essa questão do preconceito desde que eu me entendo por gente...".

Para o limite de nossa investigação, reporto-me a algumas postagens divulgadas nas redes sociais e que exemplificam a natureza dos comentários caracterizados pelo apresentador em relação ao tema.

Vejamos a Figura 8, que segue:
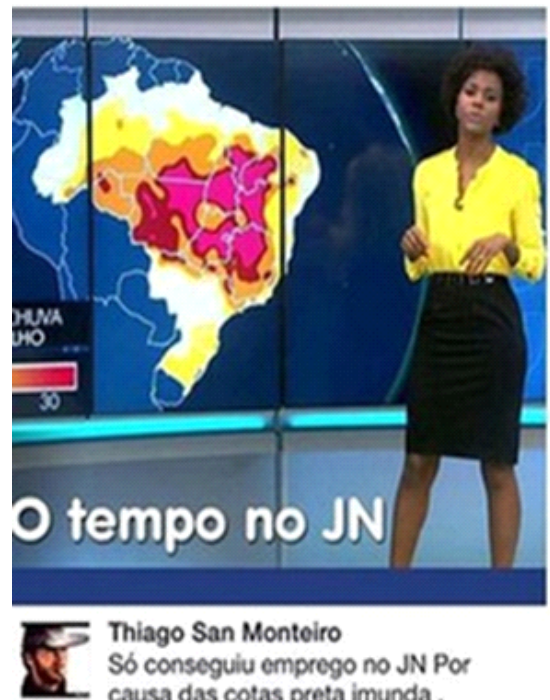

Thiago San Monteiro

Só conseguiu emprego no JN Por

causa das cotas preta imunda.

his 2 horas : Curtic - O 36 . Pesponder

Gulliermo Bitencourt respo... - 2 respostas

\section{Thiago San Monteiro}

Tempo branco? mentira, sua preta.

his 2 horas : Curtir - 0 41 - Responder

F. Gabriel Garcia Negreiros re... -9 respostas

\section{Ariel Vieira}

Só conseguiu emprego no JN Por

causa das cotas, preta macaca

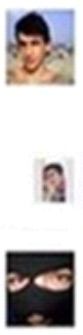

Arthur Frey

Qual é band-aid de preto?

R: Fita isolante

his 2 horas : Curtir - $D$ 17- Responder

lago Filpo Ferreira respondeu $: 2$ respostas

Karl Jagger

Năo bebo caté pra năo ter intimidade

com preto.

bil 2 horas : Curtir - $D 71$ - Responder

Mariano Fabiolo respondeu - 15 respostas

Folipe Santos

Ela ja nasceu de luto

Nu 2 horas - Curtir D 51 . Pesponder

\section{Arthur Frey}

O que são 100000000 de pretos na

lua?

R: Um eclipse total!

his 2 horas - Curtic - $D 28$ - Responder

Maria Eduarda Bellai

Em pleno século 2015 ainda temos

preto na TV

Hat 1 hoea - Curtic s 9 - Responder

Yasmim Queiroz respondeu - 39 respostas

\section{Chronick Schlage}

Só foi ela chegar ai que o tempo ficou seco igualmente a um carvăo em , cinzas.

Fonte: <https:// favelapotente.files.wordpress.com/2015/07/maju.jpg>.

Figura 8: Amostra de comentários preconceituosos a respeito de Maria Júlia Coutinho na web 
A Figura 8 destaca uma amostragem dos comentários mencionados na reportagem transcrita e serão reproduzidos em função da análise do tipo de estratégia empreendido para o posicionamento sobre o tema pelos usuários. De fato, constatamos a manifestação do preconceito, a partir das nove postagens observadas na Figura 8. Elas se dirigem à vítima, enfatizando o lado profissional e a sua etnia, através de piadas estereotipadas. Ao destacar o âmbito profissional, o argumento ora remete às cotas ora remete à função de apresentadora do tempo, conforme os Exemplos 6 e 7, a seguir:

Exemplo 6

"só conseguiu emprego no JN por causa das cotas preta imunda".

A postagem explicitada no Exemplo 6 aciona um conhecimento estruturado e seletivo em torno do sistema de cotas, medida que não é considerada justa para alguns membros da sociedade. Nesse caso, o usuário lança mão de estratégias cognitivas, recorrendo ao conhecimento partilhado para produzir sentido, promovendo a adesão do leitor seja pela informação que acrescenta, seja pela adesão ao seu posicionamento. Estratégia diferente é o que evidencia o exemplo que segue. Vejamos:

Exemplo 7

"só foi ela chegar ai que o tempo ficou seco igualmente a um carvão em cinzas".

O Exemplo 7 revela, por parte do leitor, o emprego da expressão "foi só ela chegar aî" para produzir um novo sentido, relacionando a presença da apresentadora no ambiente do jornal à função de apresentadora do tempo. A estratégia do usuário é relacionar o uso do jargão de quem anuncia as condições do tempo - em "o tempo ficou seco" - à insatisfação de sua presença na emissora, ao comparar "ela" com "igualmente a um carvão em cinzas”. Percebe-se, contudo, que tal insatisfação não está relacionada ao seu desempenho, mas a um juízo de valor metafórico, em relação a um tempo ruim atribuído à sua presença. $\mathrm{O}$ exemplo em tela apoia-se na emergência de múltiplas e contínuas ressignificações da tessitura do texto e do intertexto, movido pela heterogeneidade e imprevisibilidade da produção de sentido. Vejamos o próximo exemplo: 
Exemplo 8

"o que são 100000000 pretos na lua? R. Um eclipse total"

O Exemplo 8 registra a presença de uma pergunta para tratar o tema. A manifestação do preconceito aparece como uma expressão individualizada e com base nos conhecimentos de mundo e compartilhados por sujeitos de uma cultura em que o negro não tinha uma função social e econômica relevante. Além disso, com a piada, o leitor utiliza o que Koch e Elias (2006) denominam conhecimento comunicacional, levando em conta um certo modo de dizer com a quantidade de informação adequada e seleção vocabular para, em tom jocoso, produzir sentido pejorativo sobre o tema.

Os Exemplos 6, 7 e 8 constituem registros em que os leitores revelaram as múltiplas possibilidades de sentidos atribuídas às formas de conhecimentos (textuais, de gêneros, de mundo, dentre outros) que eles dominam. A mobilização dessa diversidade de formas sinaliza que uma prática não escolarizada de leitura define-se não pelo tema ou texto em si, mas pelo sujeito, influenciado por um contexto ideológico dinâmico e vinculado aos momentos histórico-sociais que perpassam seu inconsciente (CORACINI, 2005).

A próxima figura ilustra um conjunto de comentários produzidos no intuito de revelar solidariedade à vítima e, embora oportunizem um posicionamento contrário, sinalizam para conclusões semelhantes às postagens referentes à Figura 8. Vejamos esses comentários na figura que segue: 


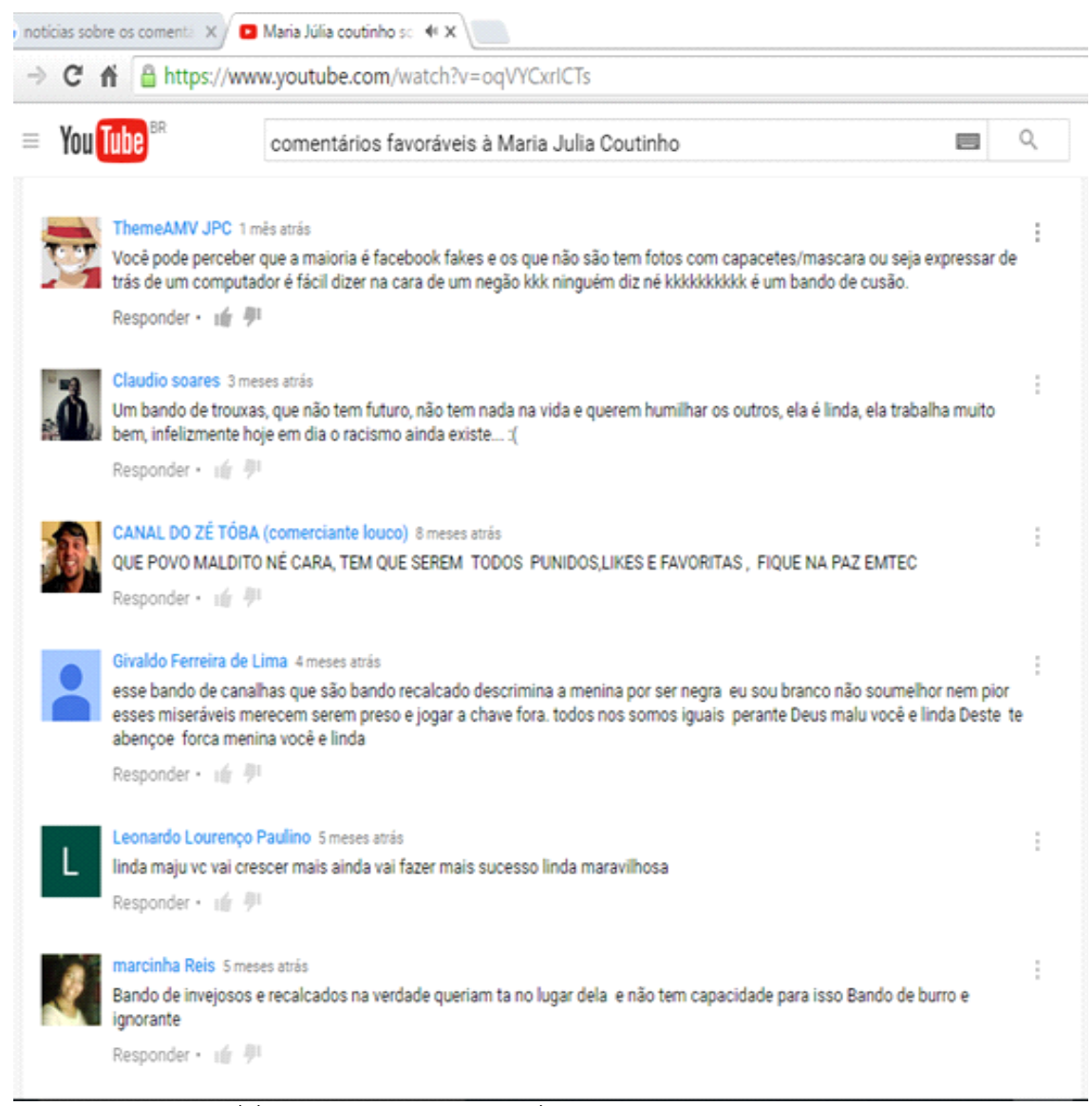

Fonte: <https://www.youtube.com/watch?v=oqVYCxrICTs $>$.

Figura 9: Amostra de comentários de apoio a Maria Júlia Coutinho na web

A Figura 9 destaca seis comentários gerados após a manifestação de preconceito contra Maria Júlia Coutinho e se dirigem aos sujeitos implicados: vítima e algozes. Os exemplos que seguem, retirados da figura supracitada, representam uma amostragem da solidariedade anunciada. Destacamos dois exemplos para cada destinatário observado. Vejamos o Exemplo 9: 


\section{Exemplo 9}

"a maioria é facebook fakes e os que não são tem fotos com capacetes/mascara ou seja expressar de trás de um computador é fácil dizer na cara de um negão kkk ninguém diz né kekek um bando de cusão".

O posicionamento expresso no Exemplo 9 destaca uma estratégia consciente de leitura, em que o leitor reflete e tem controle sobre seus argumentos com base em elementos textuais (KLEIMAN, 2009) reconhecíveis, como em "facebook fakes" e em "tem fotos com capacetes/máscara". A utilização desses elementos põe em relevo o argumento que se constrói em favor da vítima, bem como reitera o posicionamento do leitor em relação à acusação de oportunismo ante o fragmento "expressar de trás de um computador é fácil dizer na cara de um negão kkk ninguém diz...”. As relações interpessoais tornam-se mais relevantes do que a referencialidade explicitada no início do posicionamento. Vamos ao registro do próximo exemplo:

\section{Exemplo 10}

"Um bando de trouxas, que não tem futuro, não tem nada na vida e querem bumilhar os outros, ela é linda, ela trabalha muito bem, infelizmente hoje em dia o racismo ainda existe ..."

O Exemplo 10, diferentemente do anterior, expressa um juízo de valor, através de termos como "bando de trouxas" e "não tem futuro". O argumento do leitor é construído a partir da expectativa de que os criminosos, embora não tenham prestígio e sejam de classe social inferior, querem humilhar quem tem - no caso, a jornalista, representada pelo pronome "ela". Esse tipo de processamento revela uma atividade mental em que o leitor constrói o sentido com base no senso comum contido em clichês, a exemplo da ideia de que "pobre não tem futuro", "pobre é revoltado".

Essas constatações vão ao encontro do que Coracini (2005) menciona sobre a regulação da produção de certos sentidos em detrimento de outros. O dizer está condicionado à repercussão dos movimentos sociais em defesa dos direitos humanos, promovendo vários desdobramentos na maneira de conceber o sujeito e suas relações com o outro. Os comentários não definem uma fronteira clara entre o que se atribui à vítima e o que se atribui aos 
criminosos, o fragmento, “... não tem nada na vida e querem humilhar os outros..." parece vago ou deslocado como argumento em defesa da vítima.

Vejamos o exemplo que segue, em que o posicionamento se dirige à apresentadora:

Exemplo 11

"Bando de invejosos e recalcados na verdade queriam tá no lugar dela e não tem capacidade para isso Bando de burro e ignorante".

O comentário revelado no Exemplo 11 baseia-se na capacidade profissional da apresentadora, embora esse posicionamento parta de uma inferência não autorizada, que apela para o senso comum. Para se chegar "no lugar dela" é preciso demonstração de uma capacidade acima da média, suposta pelo leitor, e impossível de ser atingida pelos criminosos. Vejamos o exemplo seguinte:

Exemplo 12

"linda maju ve vai crescer mais ainda vai fazer mais sucesso linda maravilhosa"

O Exemplo 12 destaca o elogio à aparência física como uma forma de se solidarizar com a dor alheia. Nesse caso, a estratégia parece ser motivacional e obedece ao princípio da criação de expectativas em relação ao destino da polêmica. O trecho, "vc vai crescer mais ainda" parece evidenciar que o preconceito de que está sendo vítima trará benefícios em forma de compensação, tornando-a mais bem-sucedida. A produção de sentidos está expressa nesta impressão afetiva para registrar a solidariedade. Não se pode mudar a condição de ser negra, mas ao acreditar em sua própria beleza e sucesso pode-se mudar o destino. Trata-se de um comentário em direção à autoestima da apresentadora.

De modo geral, os fragmentos refletem uma dada produção de sentidos mobilizados a partir da noção de que "o texto forma uma rede em várias dimensões e se dá como um complexo processo de mapeamento cognitivo de fatores a serem considerados na sua produção e recepção" (MARCUSCHI, 2009). Por essa razão, o sentido é construído na interação, conferindo a convicção de que não basta reconhecer palavras e frases. Nessa 
interação, há que se considerar as experiências e os conhecimentos do leitor.

Nesse sentido, os Exemplos 6 e 9 representam um expoente dessa interação para a competência comunicativa. Apesar de posicionamentos divergentes em relação ao tema, ambos revelam uma competência comunicativa regulada por uma produção de sentido que vai além da percepção do sujeito como gerador, pois informações de base linguísticotextuais atravessam o posicionamento mencionado. Pela presença dessa condição, os exemplos se aproximam de práticas escolarizadas. Diferentemente, os Exemplos 7, 8, 10, 11 e 12 evidenciam modos de produção de sentido em que os argumentos que sustentam a posição dos leitores estão relacionados a experiências diversas, da individual à coletiva, influenciadas por contextos socioculturais e ideológicos, mais distantes do horizonte escolar, o que destacaria a evidência de práticas não escolarizadas.

\section{Sobre os Textos, o Ensino de Leitura e a Formação de Leitores nas Mídias}

Os textos das mídias, tomados como ponto de partida para a análise das práticas de leitura evidenciada nas atividades e nos comentários sobre o racismo, permitiram algumas reflexões a serem apontadas no tópico em curso. A primeira delas diz respeito à diversidade de textos e às práticas de leitura mobilizadas. Vejamos o quadro-síntese que segue:

Quadro 1: Diversidade de práticas de leitura mobilizada nos textos

\begin{tabular}{|c|c|c|}
\hline $\begin{array}{c}\text { Textos/Práticas } \\
\text { de leitura }\end{array}$ & Mídia Impressa & Mídia digital \\
\hline Diversidade textual & Crônica, cartuns (LD) & $\begin{array}{c}\text { Reportagem, notícia, } \\
\text { comentários (Redes Sociais) }\end{array}$ \\
\hline $\begin{array}{c}\text { Práticas de leitura } \\
\text { escolarizadas }\end{array}$ & $1,2,3,4$ (Atividades) & 6,9 (Comentários) \\
\hline $\begin{array}{c}\text { Práticas de leitura } \\
\text { não escolarizadas }\end{array}$ & 5 (Atividades) & $7,8,10,11,12$ (Comentários) \\
\hline
\end{tabular}


O Quadro 1 permite constatar a intertextualidade como aspecto essencial para a produção de sentidos em relação à temática. Trata-se de um dos fatores que envolve a ação dos sujeitos (de ordem pragmática) para construir sentidos possíveis, em função de várias ações e sanções que o texto, enquanto tecido, sofre (MARCUSCHI, 2009, p. 40). Relacionar essa concepção a uma prática pedagógica de leitura é considerar que os sujeitos necessitam articular e dominar conhecimentos (linguísticos, contextual e de gêneros) em função da adequação do contexto de interlocução (ABREU, 2014).

Outra constatação é a de que tanto a mídia impressa quanto a mídia digital destacam práticas escolarizadas e não escolarizadas. O resultado dessa constatação poderia sinalizar uma situação ideal para a formação de leitores, caso a mobilização dessas práticas fosse menos marcada. Entretanto, não é o que acontece.

A predominância de práticas escolarizadas na mídia impressa (Exemplos 1, 2, 3 e 4) em detrimento de práticas não escolarizadas na mídia digital (Exemplos 7, 8, 10, 11 e 12) indica uma polarização muito marcada. Isto é, de um lado, têm-se as práticas requeridas no LD, sinalizando a produção de sentido centrada no texto; de outro lado, têm-se as práticas demonstradas nos comentários, apontando para o posicionamento dos sujeitos. O que se espera, contudo, é que o avanço no mundo digital seja aproveitado pelas instituições escolares, considerando o que se deve adotar como inovador e o que se deve manter como significativo. Para isso, é necessária uma consciência de que "não são os recursos que definem a aprendizagem, são as pessoas, o projeto pedagógico, as interações, a gestão" (MORAN, 2013, p. 12). Cabe, no que compete ao docente, agir como mediador de práticas que integrem os conhecimentos adquiridos em contexto escolarizado com os que trazem de situações reais, potencializando a aprendizagem para as múltiplas funções sociais da escola, no sentido de cooperar para a construção de sujeitos mais responsáveis socialmente.

Assim, insistir na formação de leitores proficientes é investir numa ação de planejamento docente que considere o sujeito (e sua formação social, histórica, cultural e ideológica), o texto (nas diversas situações de interlocução e de gêneros discursivos, implicados num continuum de habilidades) e os suportes midiáticos que veiculam a diversidade textual. 
Para os suportes midiáticos, a incorporação da tecnologia digital como um recurso que introduz novas ações de linguagem tem sido alardeada em livros didáticos. Entretanto, um estudo exploratório realizado por Rafael e Silva (2015), com base na análise de recursos tecnológicos presentes em livros didáticos como ação de planejamento de leitura, constatou que as práticas letradas digitais funcionam mais como um recurso motivacional do que metodológico. Ora, se o livro didático é responsável por nortear a maioria das práticas docentes em contexto escolar, urge repensar um fazer metodológico que considere a mídia digital como objeto de estudo e de ensino relevante e complementar com o intuito de reconfigurar práticas de leitura necessárias à formação de leitores para atuarem em vários contextos, não só o escolar.

\section{Considerações Finais}

As considerações finais para o que me proponho a refletir, neste artigo, a partir da análise de práticas de leitura (escolarizadas e não escolarizadas) mobilizadas em dois conjuntos de dados, se destacam por duas observações. A primeira diz respeito ao questionamento sobre a necessidade de novas configurações (ou não) para a formação de leitores competentes comunicativamente. A resposta aponta para uma posição afirmativa. Sim, há a necessidade de novas configurações para a formação de leitores. Em se tratando do ensino de texto e de leitura, a noção de competência comunicativa extrapola a mobilização das estratégias para a produção de sentido que envolve apenas o texto, como as práticas requeridas no LD; são necessárias estratégias que resgatem o posicionamento do sujeito conforme as evidências constatadas nos comentários. Além disso, o comportamento divergente para a produção de sentido, em ambas as situações, sinaliza uma contínua tensão no tratamento dado aos textos e à leitura, destacando a necessidade de ações de planejamento de ensino, que considerem a relação entre a diversidade textual e os múltiplos suportes midiáticos para a formação de leitores em sintonia com novas práticas.

A segunda consideração toma o termo "ação de ensino" como basilar para uma nova configuração sobre o ensino de texto e de leitura, permeado por duas constatações que devem estar presentes no planejamento docente: 
1. Necessidade de um saber de referência, que deixe claro uma resposta para $o$ que se ensina quando se ensina leitura?; e 2. Evidência de um saber metodológico, que permita uma operacionalização para como relacionar aspectos da mídia digital ao contexto de sala de aula, a leitura no papel? Dito de outra forma, dimensionar uma ação de ensino sobre um objeto, mesmo que seja leitura, bastante estabilizado na produção acadêmica e nos materiais didáticos disponibilizados, implica considerar ações cujas etapas conceituais, metodológicas e avaliativas estejam claramente articuladas ao uso e à produção desses objetos em contexto de educação básica.

\section{Referências}

ABREU, M. T. T. V. Revendo o processo ensino-aprendizagem da leitura e da escrita no ensino fundamental. In: SIMÕES, D. M. P.; FIGUEIREDO, F. J. Q. Metodologias em/de Linguística Aplicada para ensino e aprendizagem de linguas. Campinas, SP: Pontes, 2014. p. 119-152.

ANTUNES, I. Lingua, texto e ensino: outra escola possível. São Paulo: Parábola, 2009.

ARAÚJO, D. L. de. Objeto de ensino: revisão sistemática e proposição de conceito. In: SIMÕES, D. M. P.; FIGUEIREDO, F. J. Q. Metodologias em/de Linguistica Aplicada para ensino e aprendizagem de línguas. Campinas, SP: Pontes, 2014. p. 221-246.

BRONCKART, J.-P. O agir nos discursos: das concepções teóricas às concepções dos trabalhadores; Trad. Anna Rachel Machado; Maria de Lourdes Meirelles Matencio. Campinas: Mercado de Letras, 2008.

BUIN, E. A construção do sentido em textos escolares: entre versões e mediações. In: SIGNORINI, I. (Org.) Significados da inovação no ensino de Lingua Portuguesa e na formação dos professores. Campinas: Mercado de Letras, 2007. p. 47-78.

CEREJA, W. R.; MAGALHÃES, T. C. Português: linguagens. $8^{\circ}$ ano. São Paulo: Atual, 2014. 
CORACINI, M. J. R. F. Concepções de leitura na (pós)modernidade. In: LIMA, R. C. de C. (Org.). Leitura: múltiplos olhares. Campinas: Mercado de Letras; São João da Boa Vista: Unifeob, 2005. p. 15-44.

FREIRE, F. M. P. Formas de materialidade lingüística, gêneros de discurso e interfaces. In: SILVA, E. T. da et al. A leitura nos oceanos da internet. 2. ed. São Paulo: Cortez, 2008. p. 65-88.

KLEIMAN, A. Texto \& leitor: aspectos cognitivos da leitura. 12. ed. Campinas: Pontes, 2009.

KOCH, I. V.; ELIAS, V. M. Ler e compreender. os sentidos do texto. São Paulo: Contexto, 2006.

MARCUSCHI, L. A. Linguística de texto: o que é e como se faz? Recife: Ed. Universitária da UFPE, 2009.

MORAN, J. M. Novas tecnologias e mediação pedagógica. 21. ed. Campinas: Papirus, 2013.

RAFAEL, E. L.; SILVA, W. M. da. Utilização de recursos tecnológicos em livros didáticos de português como ação de planejamento. LinguíStica, Rio e Janeiro, v. 11, n. 2, p. 262-277, dez. 2015. Disponível em: <https:// revistas.ufrj.br/index.php/rl/article/view/4513/3284>.

SILVA, E. T. da. Formação do leitor virtual pela escola brasileira: uma navegação por mares bravios. In: SILVA, E. T. da et al. A leitura nos oceanos da internet. 2. ed. São Paulo: Cortez, 2008. p. 115-126.

Recebido em: 12/04/2016

Aceito em: 13/08/2016 